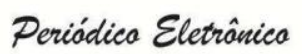

\section{ANÁLISE DA CIRCULAÇÃO URBANA NA AV. JOÃO PESSOA, CIDADE DE GUARATINGUETÁ E PROPOSTA DE INTERVENÇÃO}

\author{
Enos Arneiro Nogueira da Silva ${ }^{1}$ \\ André Luiz Cândido de Moura ${ }^{2}$
}

\section{RESUMO}

Este trabalho foi realizado com intuito de aprofundar os estudos sobre a cultura do automóvel nas cidades brasileiras. Teve como objeto de estudo a circulação urbana na Avenida João Pessoa, localizada no bairro do Pedregulho, na cidade de Guaratinguetá - SP. Mediante os resultados obtidos foi possível elaborar diretrizes para a melhoria da circulação urbana da Avenida João Pessoa. A pesquisa foi realizada mediante aplicação de questionários. Fez-se também visitas técnicas, ao longo de toda avenida, com intuito de analisar e coletar dados sobre os principais problemas nela existentes.

PALAVRAS-CHAVE: Avenida João Pessoa. Circulação urbana. Automóvel.

\section{MOVEMENT ANALYSIS OF URBAN IN AV. JOHN PERSON, GUARATINGUETÁ CITY AND INTERVENTION PROPOSAL}

\section{ABSTRACT}

This work was performed in order to deepen the studies on the automobile culture in Brazilian cities. We had as study object the urban movement in João Pessoa Avenue, located in the neighborhood of Gravel in the city of Guaratinguetá - SP. From the results obtained it was possible to draw up guidelines for the improvement of urban traffic of João Pessoa Avenue. The survey was conducted through questionnaires. It was held also technical visits, along the entire boulevard with intuited to analyze collect data on the main problems on the avenue.

KEYWORDS: Avenue João Pessoa. Urban traffic. Car.

\section{MOVIMIENTO DE ANÁLISIS URBANO EN AV. JOHN PERSON, GUARATINGUETÁ CIUDAD Y PROPUESTA DE INTERVENCIÓN}

\section{RESUMEN}

Este trabajo se realizó con el fin de profundizar los estudios sobre la cultura del automóvil en las ciudades brasileñas. Tuvo como objeto de estudio el movimiento urbano en Avenida João Pessoa,

\footnotetext{
${ }^{1}$ Prof. Dr. UNESP Guaratinguetá. Email: enos@feg.unesp.br

${ }^{2}$ Graduado em Engenharia Civil pela Unesp - Campus de Guaratinguetá. E-mail: andre.ec08@gmail.com
} 


\section{Periódica Eletrânica

ubicada en el barrio de Pedregulho en la ciudad de Guaratinguetá - SP. De los resultados obtenidos se pudo elaborar directrices para la mejora del tráfico urbano de João Pessoa Avenue.

La encuesta se realizó por medio de cuestionarios. También hubo visitas técnicas, a lo largo de toda la avenida, con el objetivo de analizar y recopilar datos sobre los principales problemas en la avenida.

PALABRAS CLAVE: Avenida João Pessoa. El tráfico urbano. Coche.

\section{INTRODUÇÃO}

No Brasil Colônia, nas primeiras vilas e cidades, havia poucas opções de circulação urbana, as pessoas se deslocavam caminhando, montadas em animais ou eram transportadas por escravos nas liteiras. O transporte de mercadorias e de pessoas também acontecia por meio da navegação.

Com a descoberta da máquina a vapor surgem na Europa as primeiras estradas de ferro. Aos poucos a mecanização se espalhou pelo mundo, atingindo todos os setores da sociedade, alterando significativamente o modo de circular pelas cidades, pelas vilas e pelos países.

Gradativamente o processo de mecanização se expandiu pelo mundo provocando grandes transformações na forma de transportar pessoas e mercadorias. Decorrentes deste processo surgiram os veículos automotores como trens, carros, motos e, muito tempo depois, o metrô.

Desde o início do século $\mathrm{XX}$, com a democratização do automóvel promovida por Henry Ford, o número de novos veículos não para de crescer nas cidades.

Hoje, boa parte do sistema viário brasileiro é uma herança do passado, ruas e calçadas estreitas que não atendem as exigências atuais de mobilidade urbana e não asseguram uma eficiente circulação de veículos automotores, de ciclistas e de pedestres.

É comum encontrar nas cidades brasileiras, ruas sem pavimentação, leito carroçável esburacado, avenidas em condições precárias de manutenção, inexistência de ciclofaixa ou ciclovia, estacionamentos públicos deficientes, entre tantas outras mazelas urbanas.

No Brasil com raras exceções encontra-se transporte coletivo de qualidade. Quanto ao transporte público a situação é caótica. Em geral, o que se verifica são ônibus, trens e metrôs superlotados, sem conforto, sem manutenção, sem 


\section{Periódica Eletrânica

integração que acabam sendo uma alternativa de circulação urbana cara, lenta e estressante.

Simultaneamente ao crescimento e modernização dos municípios brasileiros ocorreu a valorização e expansão da política rodoviarista. Principalmente nos grandes centros urbanos foram abertas avenidas e alargadas as ruas, para comportar o crescente fluxo de veículos automotores.

De acordo com dados do DENATRAN (Departamento Nacional de Trânsito), no ano de 2014 o número total de automóveis no Brasil atingiu aproximadamente 48 milhões de unidades para uma população de 204 milhões de habitantes, segundo estimativa do IBGE (Instituto Nacional de Geografia e Estatística). As cidades já não comportam mais o número grande e crescente de veículos.

Sem dúvida o carro particular foi uma das grandes invenções do homem e apesar do automóvel ser considerado um avanço para a sociedade atual, de certo modo também é um retrocesso devido aos problemas diretos ou indiretos que ele causa.

No Brasil sempre houve um descompasso entre o crescimento das cidades e a modernização da malha urbana. O sistema de transporte público não expandiu e nem acompanhou o processo de modernização urbana, não acompanhou o aumento da demanda de usuários e a qualidade dos serviços do transporte urbano coletivo sempre ficou aquém das demandas do acelerado crescimento das cidades brasileiras, não sendo suficiente para transportar a grande massa de trabalhadores e cidadãos que por elas circulavam.

"O decréscimo no uso do transporte público regular, ocorre devido a redução dos investimentos, abandono de sistemas já construídos, perda da confiabilidade e atratividade do sistema" (Pires, Vasconcelos e Silva. 1997, p. 20).

Por outro lado, no Brasil, houve a supervalorização do carro alicerçada pelo estímulo governamental a cultura do automóvel, fato que associado ao sonho de consumo dos cidadãos, contribuiu para que o carro fosse encarado não mais como veículo de passeio, mas como um bem material indispensável para circular pela cidade seja para ir trabalhar, estudar ou realizar atividades de lazer.

O carro de passeio tornou-se símbolo de modernização e sinônimo de status social, levando muitos motoristas a utilizá-lo para pequenos deslocamentos. 


\section{Periódica Eletrânica

Assim sendo passou a ocupar grande destaque na cidade moderna estando fortemente presente na vida cotidiana das pessoas.

Segundo SCHOR (2008, p. 66) o carro é "símbolo de masculinidade, poder, potência e charme, o automóvel passou a ser objeto de desejo, e o principal objeto de consumo do cidadão moderno".

Diante do crescimento da cidade, da agitação da vida moderna, da morosidade e precariedade de conforto e de limpeza do transporte coletivo, uma legião de cidadãos de todas as classes sociais passaram a utilizar o veículo particular para se deslocar pelas cidades. Fato que contribuiu para relegar o transporte coletivo a um segundo plano. A princípio, as pessoas de maior poder econômico deixaram de utilizar o transporte coletivo e posteriormente foram seguidas pelas classes de menor renda.

Ainda hoje, a cultura do automóvel está fortemente presente na sociedade brasileira. As cidades tem crescido sem planejamento e sem uma política de circulação urbana moderna.

Embora seja uma alternativa sustentável, circular de bicicleta pelas grandes e médias cidades brasileiras nem sempre é seguro, uma vez que, em grande parte das ruas, não há ciclovias ou ciclofaixas.

\section{OBJETIVO}

O trabalho teve como objetivo refletir sobre a cultura do automóvel nas cidades brasileiras, mediante um estudo de caso realizado na Avenida João Pessoa, cidade de Guaratinguetá. Com base na pesquisa de campo desenvolvida elaborouse diretrizes para uma intervenção urbana na avenida de modo a contribuir para a melhoria da circulação urbana e para a construção da cidade sustentável.

Outro objetivo foi verificar a importância da Avenida João Pessoa para a melhoria da circulação urbana e cidade de Guaratinguetá e estimular o debate sobre circulação urbana na cidade sustentável. 


\section{Periódica Eletrânica

\section{METODOLOGIA}

Realizou-se um levantamento bibliográfico sobre a cidade sustentável e sobre a circulação urbana brasileira. Recorreu-se ao Museu Frei Galvão para realizar pesquisas referente a história e a evolução urbana do Bairro do Pedregulho. Foram feitas diversas visitas técnicas na Avenida João Pessoa com fim específico de coletar dados e observar a sua dinâmica urbana.

Elaborou-se um questionário o qual foi respondido por pedestres, ciclistas e motoristas que circulam pela Avenida João Pessoa. A tabulação dos dados contribuiu para as análises e elaboração deste trabalho.

\section{CIRCULAÇÃO URBANA NA ATUALIDADE}

Segundo a Carta de Atenas a cidade possui quatro funções: morar, trabalhar, lazer e circular. Ela recomenda que a cidade seja organizada de acordo com estas quatro funções e ainda com a diferenciação do uso do solo, de modo a possuir áreas específicas como: comercial, industrial, residencial entre outras.

Embora este tipo de organização espacial facilitasse a leitura do espaço urbano e a sua gestão, ela acaba estimulando o cidadão a circular e intensamente pela cidade, deslocando-se diariamente de um setor para outro, seja para trabalhar, estudar ou praticar o lazer.

As atuais condições de transporte público brasileiro e a organização da cidade baseada na Carta de Atenas acabam contribuindo e estimulando o cidadão a utilizar o carro para se locomover de um setor para outro dentro da cidade.

O automóvel "liberta" os usuários dos constrangimentos do transporte coletivo e das regras de convivência social. Estar dentro de um carro é se sentir protegido. Alia-se a esta ideia o fato de cada vez mais o cidadão desejar um carro maior e mais veloz, apesar do espaço para estacionar na cidade ser cada vez menor e a dificuldade de trafegar ser maior.

Apesar dos problemas de circulação urbana brasileira enfrentados pelas metrópoles e conhecidos por todos, muitas cidades menores adotam como correta a cultura do automóvel. 


\section{Periódica Eletrânica

De acordo com Boareto (2008, p. 76), "os responsáveis pelas políticas urbanas entendem que o automóvel é um desejo natural das pessoas e que um dia todas que utilizam o transporte público irão migrar para o automóvel".

Outro fato a ser analisado na sociedade brasileira é a presença dos carros em comunidades carentes, onde em alguns casos inclusive inexiste saneamento básico. No entanto, diante de tantas necessidades e de poucos recursos econômicos, o governo, com o aval da população acaba optando por investir em obras de asfaltamento de vias e becos. Inclusive, essas obras tem alta visibilidade.

Ao longo do século XX o poder público de diversos países promoveu grande incentivo aos automóveis. Nos Estados Unidos, por exemplo, bairros periféricos foram construídos em locais distantes estimulando os moradores a utilizarem as autoestradas, a fim de se criar uma dependência sobre o automóvel.

No Brasil o forte estímulo dado aos automóveis e a grande quantidade de veículos circulando pelas cidades passou a gerar congestionamentos cada vez maiores e mais frequentes, poluição sonora, do ar e inúmeros acidentes de trânsito. Ao criar bairros distantes, a cidade cresce, as distâncias aumentam e novas vias são criadas. A expansão urbana tem sido incentivada mediante as facilidades do uso do automóvel. A cidade cresce sem planejamento, aumenta a quantidade de vazios urbanos, sendo necessário expandir as redes de água, de esgoto e de iluminação pública o que tornam as cidades cada vez mais caras e insustentáveis, sendo necessário realizar novos e constantes investimentos ao passo que estes recursos poderiam ser aplicados na melhoria do sistema de transportes já existente.

De acordo com Pires, Vasconcelos e Silva (1997, p.19) o incentivo aos automóveis gera um círculo vicioso. Os ônibus precisam percorrer caminhos cada vez mais longos, o que diminui sua rentabilidade e aumenta o custo da passagem.

$\mathrm{Na}$ maioria das cidades brasileiras o sistema de transporte urbano atual apresenta custo elevado para a sociedade, afetando diretamente a qualidade de vida dos cidadãos.

A falta de planejamento urbano e de uma adoção de uma ideologia para nortear o crescimento das cidades tem provocado a redução das áreas verdes e a impermeabilização do solo, bem como gerado o aumento de áreas pavimentadas. As vezes para garantir a fluidez do tráfego são demolidas construções históricas e 
extintas as áreas verdes com objetivo de abrir avenidas ou construir estacionamentos.

\section{HISTÓRICO DA CICULAÇÃO URBANA NO BRASIL}

Em 1808, a corte portuguesa, após desembarcar no Brasil, estabeleceu regras para a circulação de veículos movidos por tração animal. Ainda no século XIX era comum encontrar escravos realizando transporte de cargas (através da cangalha) e de pessoas, carregando liteiras: um tipo de carruagem sem rodas, utilizadas pelas famílias ricas.

O primeiro modelo de transporte público no Brasil surgiu na cidade do Rio de Janeiro, em 1838. Era um veículo de dois andares movido por tração animal (Figura 2). Devido a concorrência, alguns donos de carruagens individuais fizeram oposição a esse novo modelo de transporte urbano. Em 1859 surge o primeiro bonde a tração animal, logo em seguida, em 1862, o antigo modelo foi substituído por outro movido a vapor.

O Rio de Janeiro foi a primeira cidade brasileira a implantar os bondes elétricos, fato ocorrido em 1892 e depois seguida por São Paulo, em 1900. Nestas cidades o serviço de bondes funcionava mediante pequenas concessões, sem licitação. A Light, companhia de capital estrangeiro, adquiriu as principais operadoras e atuava no Rio de Janeiro. Na cidade de São Paulo, a empresa Cia. de Viação Paulista ${ }^{3}$ detinha o monopólio dos bondes elétricos.

\footnotetext{
${ }^{3}$ A empresa Companhia Viação Paulista, empresa de capital nacional, faliu após um ano da sua criação, sendo comprada pela Light, que passou a deter o monopólio dos bondes da cidade de São Paulo.
} 


\section{Periódica Eletrânica ISSN 1980-0827 \\ Fórum Ambiental \\ Volume 11, Número 03, 2015 \\ da Alta Paulista \\ Cidades Sustentáveis}

Figura 1 - Primeiro “ônibus” do Brasil

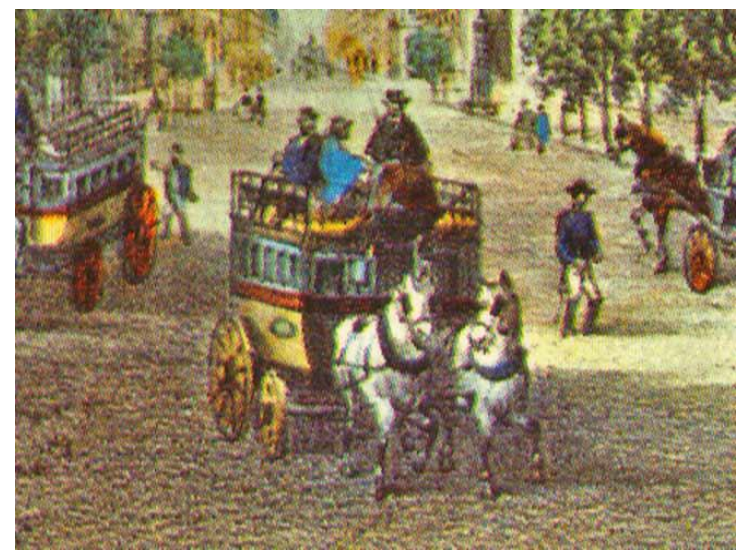

Fonte: http://www.museudantu.org.br

Entre 1920 e 1940 o transporte público nas maiores cidades brasileiras que era realizado por meio de bondes elétricos, atingiu o ápice. Entretanto a partir da década de 1950 iniciou o processo de decadência dos bondes elétricos devido aos inúmeros problemas técnicos, operacionais e a defasagem tecnológica, além da ausência de correção nas tarifas.

Em 1908 surgia no Rio de Janeiro o primeiro ônibus a gasolina, serviço que prosperou nos anos seguintes. Nas décadas de 1950 e 1960 as cidades brasileiras aderiram ao ônibus como principal meio de transporte urbano, o qual persiste até hoje.

Segundo Oliveira (2011, p. 24), o primeiro registro da circulação de um automóvel no Brasil data de 1893. Nesta época, as famílias ricas começaram a importar veículos motorizados. A partir de então o carro de passeio passou a ser o sonho de consumo de muitas famílias.

No governo de Washington Luiz houve grande incentivo para a expansão da cultura do automóvel. De acordo com Lagonegro (2008, p. 41), após eleito o presidente, adotou um discurso contra o transporte ferroviário, dizendo que as ferrovias deveriam ser substituídas pelas rodovias.

Em 1919, a Ford se instalou no Brasil sendo a primeira montadora de automóveis no país seguida pela Chevrolet, em 1925.

No governo de Getúlio Vargas foi criada a Companhia Siderúrgica Nacional - CSN, a Petrobrás e a Fábrica Nacional de Motores as quais contribuíram para consolidar a ideologia rodoviarista no Brasil, entretanto foi Juscelino Kubitschek que deu grande incentivo às indústrias automobilísticas. 


\section{Periódica Eletrânica

Na cidade de São Paulo, em 1974, foi inaugurada a primeira Estação do Metrô do país, a linha azul, desde então tem ocorrido uma lenta expansão do transporte metroviário. Em média, por ano, na cidade de São Paulo são criados $2 \mathrm{~km}$ de linhas. Mesmo diante desta dificuldade hoje o metrô é considerado um marco no transporte público brasileiro.

A partir de 1975, devido a crise do petróleo iniciada em 1973, o governo brasileiro implantou o programa Proálcool ${ }^{4}$, o que incentivou, ainda mais o transporte individual.

No período entre 2000 e 2010 o Brasil obteve um próspero desenvolvimento econômico que provocou o aumento de renda de grande parte da população. Por causa deste crescimento houve uma maior demanda pelo transporte público e também aumentou o número de cidadãos que passaram a ser usuários do transporte particular individual.

Recentemente o Governo Brasileiro reduziu o IPI (Imposto Sobre Produtos Industrializados) para veículos novos ${ }^{5}$, para incentivar o mercado automobilístico. Esta medida incentivou ainda mais o transporte individual.

Em relação as bicicletas, segundo Oliveira (2011, p. 21), não se sabe a data da chegada dos primeiros modelos ao Brasil, no entanto, muitos pesquisadores afirmam que as primeiras chegaram na região sudeste, no eixo Rio-São Paulo, onde moravam as famílias de alto poder aquisitivo.

Em 1948, iniciou-se a fabricação de bicicletas no Brasil, houve considerável aceitação delas pela classe trabalhadora. No entanto, as cidades cresceram de forma a estimular a cultura do automóvel, de maneira que as bicicletas foram relegadas a segundo plano. Hoje, nas cidades brasileiras as bicicletas disputam espaço com os automóveis, ônibus, motos e até mesmo carroças. Uma circulação caótica, injusta que reflete a falta de planejamento urbano.

\section{BAIRRO DO PEDREGULHO E AVENIDA JOÃO PESSOA}

Em Guaratinguetá, o bairro do pedregulho surgiu a beira de um antigo caminho de tropeiros e boiadeiros, ao lado da margem esquerda do Rio Paraíba.

\footnotetext{
${ }^{4}$ O Proálcool foi um programa do Governo Federal para substituir a gasolina pelo álcool etílico em decorrência dos preços elevados do barril de petróleo na época.

${ }^{5}$ A redução do IPI para alguns modelos de veículos novos foi estabelecida pela primeira vez em janeiro de 2009.
} 
Após a criação do bairro do Pedregulho, no século XIX, houve a necessidade de interligar o bairro ao centro da cidade para melhor atender os moradores. Em 1898 a Companhia Ferro Carril de Guaratinguetá instalou trilhos para bondes, puxados por tração animal, na Avenida João Pessoa. Ao longo do século XX, o bairro do Pedregulho se desenvolveu consideravelmente, principalmente ao redor da Avenida João Pessoa.

Há mais de uma década o trânsito da Avenida João Pessoa é intenso. $O$ constante e acelerado crescimento comercial do Pedregulho já demonstrava a necessidade de realizar estudos aprofundados sobre o bairro.

Hoje, na Avenida João Pessoa ocorrem congestionamentos nas horas de pico, devido a grande concentração comercial e também pelo fato da avenida servir rota de passagem para vários bairros periféricos e para a Escola de Especialistas de Aeronáutica (EEAR). Durante o horário comercial é difícil estacionar na Avenida João Pessoa. São poucos os estabelecimentos comerciais que contam com bicicletário. Trafegar de bicicleta pela avenida é arriscado assim como, para o pedestre. É uma avenida perigosa para pedestres, ciclistas e motoristas.

A Avenida João Pessoa possui calçadas razoáveis, porém em alguns trechos elas são irregulares. Ao longo de quase 2 quilômetros de extensão da avenida há diversas faixas para travessia de pedestre, entretanto atravessá-las é difícil, demorado e exige muito cuidado, pois os veículos automotores, em geral, não respeitam os pedestres. Praticamente em todos os cruzamentos há um semáforo programado inclusive para a travessia de pedestres.

Figura 2 - Avenida João Pessoa, destacada pela cor azul.

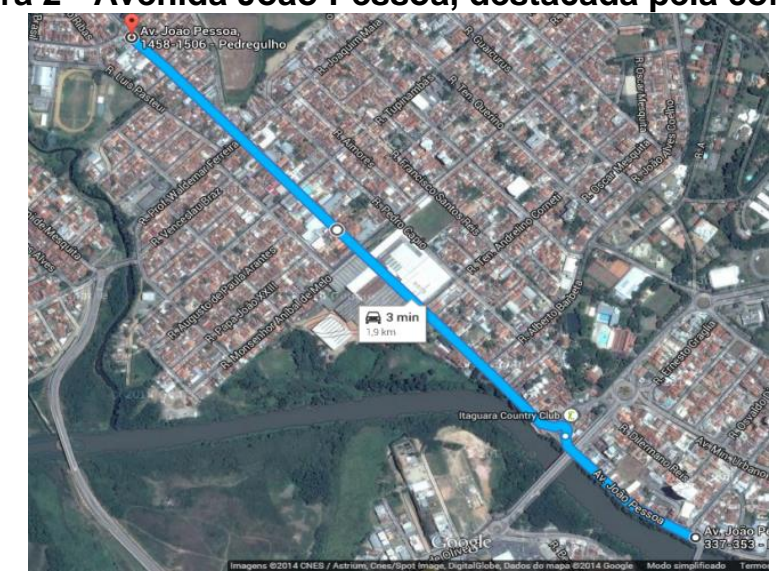

Fonte: Google Maps 


\section{Periódica Eletrânica

\section{CIRCULAR DE BICICLETA NA CIDADE CONTEMPORÂNEA}

A bicicleta, sendo um meio de locomoção de baixo custo e de fácil manutenção é utilizada principalmente por pessoas de baixo poder aquisitivo, o uso dela deveria ser incentivada de modo a atingir a grande maioria da população. $\mathrm{Na}$ Avenida João Pessoa o tráfego de automóveis predomina. Há um conflito latente entre motoristas e ciclistas. Nela não há locais exclusivos para circulação de bicicletas. Não há ciclovias ou ciclofaixas. O espaço que deveria ser destinados a ciclovia é utilizado para estacionamento de carros, forçando os ciclistas a transitarem no leito carroçável junto ao intenso movimento de veículos automotores. Circular de bicicleta pela cidade é perigoso, pois hoje impera a "lei do mais forte", o desrespeito e a imprudência.

Em vários trechos, ao longo da avenida, é permitido o estacionamento de veículos automotores e de ônibus de turismo religioso, entretanto são poucos os bicicletários.

\section{POLOS GERADORES DE TRÁFEGo}

Segundo o Manual de Procedimentos para o Tratamento de Polos Geradores de Tráfego (DENATRAN/FGV, 2001, p. 08),

Os polos geradores de tráfego são empreendimentos de grande porte que atraem ou produzem grande número de viagens, causando reflexos negativos na circulação viária em seu entorno imediato e, em certos casos, prejudicando a acessibilidade de toda a região, além de agravar as condições de segurança de veículos e pedestres.

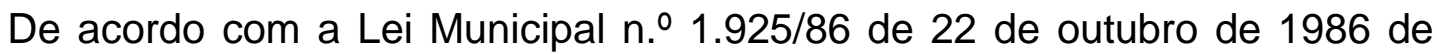
Guaratinguetá, atualizada em 2010, os principais comércios e serviços geradores de tráfego compreendem:

a) Lojas de departamentos, supermercados e centros de compras, com área construída superior a 1.200,00 $\mathrm{m}^{2}$;

b) Estabelecimentos de comércio atacadista ocupando lotes de área superior ou igual a $1.000,00 \mathrm{~m}^{2}$ e inferior a $5.000,00 \mathrm{~m}^{2}$;

c) Estabelecimentos de comércio de veículos motorizados ou máquinas de grande porte com área construída superior a 2.000,00 m²;

d) Estacionamento ou garagens de firmas transportadoras;

e) Hospitais, Prontos-Socorros e Ambulatórios com área construída superior a $1.000,00 \mathrm{~m}^{2}$

Baseados na referida lei afirma-se que na Avenida João Pessoa há estabelecimentos considerados Polos geradores de tráfego. São eles:

a) $\operatorname{AME}$ (Ambulatório Médico de Especialidades), 
b) Sociedade de Amigos do Bairro do Pedregulho (SABAP),

c) Centro Comercial recentemente construído e inaugurado em 2014, o qual possui diversas lojas e permite a circulação de pedestres entre a $A v$. João Pessoa e a Rua. Prof. Carlos Alvin Taques Bitencourt,

d) Há também locação de edifícios para igrejas, agências bancárias e comércio de médio porte.

\section{ANÁLISE dOS RESULTADOS DA PESQUISA DE CAMPO}

A pesquisa de campo realizada mediante a aplicação de questionários teve como público-alvo moradores da cidade de Guaratinguetá que circulavam pela Avenida João Pessoa. Cada entrevistado dispendeu no máximo cinco minutos do seu tempo para responder as 31 perguntas.

Exigiu-se dos entrevistados a idade mínima de 18 anos e transitar com frequência pela avenida. As primeiras 6 perguntas do questionário eram de identificação.

Observou-se que a maioria dos entrevistados (54\%) possui ao menos o ensino médio concluído. Do restante, 35\% disseram ter nível superior. Nenhum dos entrevistados disse ser analfabeto.

Notou-se que $50 \%$ dos entrevistados são jovens. Sendo que $85 \%$ tem menos de 50 anos. Idosos são apenas $4 \%$.

A Avenida João Pessoa é frequentada, em grande maioria, por trabalhadores. Do total de entrevistados, $44 \%$ trabalham na avenida e apenas $8 \%$ moram em casas localizadas na avenida.

De acordo com 39\% dos entrevistados, as calçadas são ruins. Quando perguntado sobre a facilidade de caminhar pela avenida, $23 \%$ dos pedestres afirmaram que sentem dificuldades. O mesmo ocorre com cadeirantes e idosos, sendo que nesses casos as dificuldades são maiores, pois nem sempre há rampas. Quanto a segurança para atravessar a avenida, $58 \%$ avaliaram como ruim enquanto que $19 \%$ disse ser regular. Para $69 \%$ dos entrevistados é difícil atravessar a avenida.

A iluminação pública foi avaliada como sendo regular (46\%) e 15\% disseram ser ruim. 


\section{Fórum Ambiental}

Volume 11, Número 03, 2015

da Alta Paulista

\section{Cidades Sustentáveis}

De acordo com $61 \%$ dos entrevistados (gráfico 1), a Avenida João Pessoa possui leito carroçável de boa qualidade, apenas uma minoria de $8 \%$ classificou como sendo ruim. Quanto a sinalização de trânsito da Avenida João Pessoa 38\% dos entrevistados afirmaram que é boa.

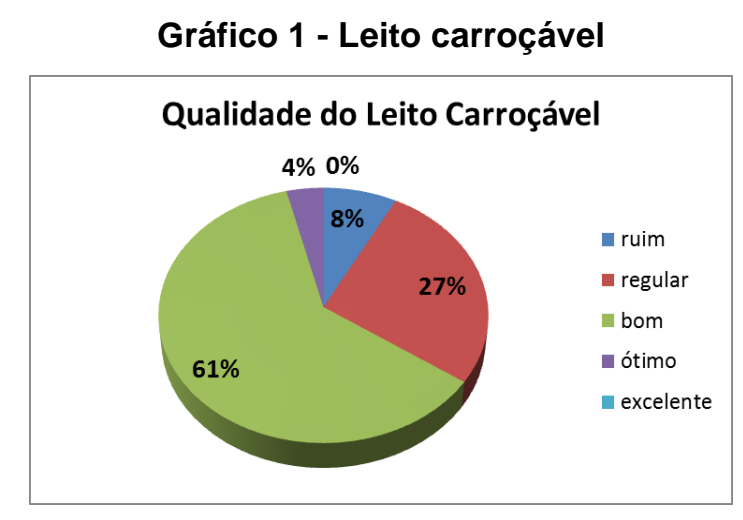

Fonte: do próprio autor

A grande maioria (96\%) diz que há necessidade de uma ciclovia na Avenida João Pessoa. Poucos entrevistados (23\%) utilizam a bicicleta para lazer e $42 \%$ deles responderam que não a utilizam. Somente $35 \%$ afirmaram utilizar a bicicleta para trabalhar.

Quanto aos bicicletários distribuídos ao longo da avenida, a grande maioria (77\%) afirmou que é ruim.

Em relação ao transporte coletivo, $22 \%$ dos entrevistados usam diariamente, entretanto, mais da metade (52\%) não faz uso desse transporte (gráfico 2). A maioria (67\%) não está satisfeita com os horários disponíveis das linhas de ônibus.

Para $69 \%$ dos usuários a quantidade de pontos de ônibus é suficiente, entretanto, ao perguntar sobre a sua qualidade, a maior parte ficou dividida entre regular $34 \%$ e bom para $31 \%$.

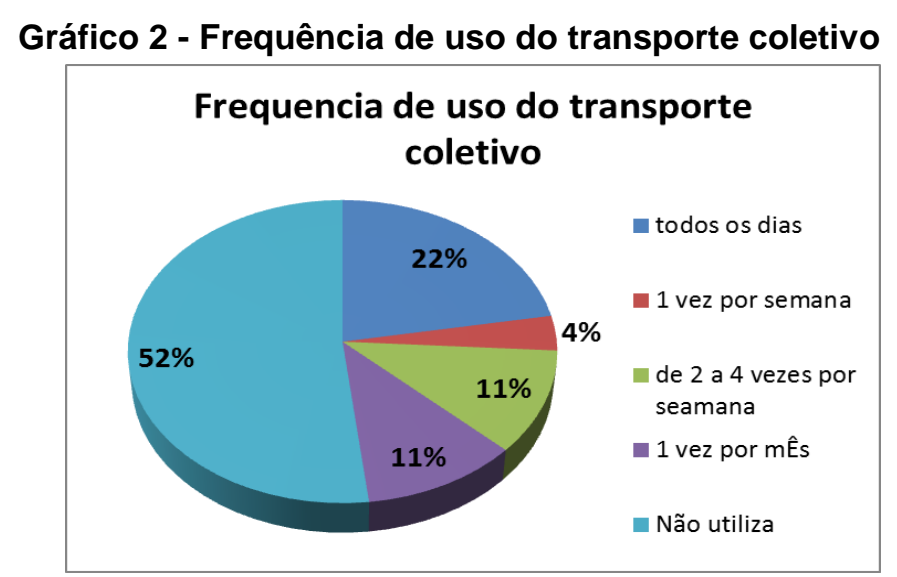

Fonte: do próprio autor 


\section{Periódica Eletrânica

A Avenida João Pessoa é utilizada para atividade de lazer, como caminhadas, corrida e esportes. Dos entrevistados $58 \%$ afirmaram utilizá-la para esta finalidade. Sobre assaltos e roubos, $80 \%$ afirmam que nunca foram vítima de assalto na Avenida João Pessoa.

Apenas 35\% dos entrevistados consideram a Avenida João Pessoa agradável. A limpeza urbana foi considerada ruim por $65 \%$. A arborização foi classificada como sendo regular por $38 \%$ enquanto para $31 \%$ é ruim. A grande maioria, $85 \%$ diz que ela possui intenso fluxo de carros. A Avenida João Pessoa foi avaliada como barulhenta por $92 \%$ dos entrevistados.

\section{CONCLUSÃO}

Atualmente, nas cidades brasileiras os ônibus e automóveis estão ocupando o lugar que antigamente era dos bondes. A cultura do automóvel se alastrou por todo o país. $\mathrm{O}$ transporte ferroviário foi relegado a um segundo plano. Ainda hoje a combinação de diversos fatores como a redução do IPI, pressões de empresas multinacionais e propagandas nos meios de comunicação, tem contribuído para perpetuar a cultura do automóvel.

Guaratinguetá não foge a regra e também vivencia a cultura do automóvel. Assim como a maioria das cidades, enfrenta os problemas ambientais e urbanos decorrentes desta "epidemia". A poluição sonora, a fumaça, o gás carbônico e os congestionamentos têm provocado grandes males aos cidadãos, tornando-os cada dia mais irritados e agressivos.

$\mathrm{Na}$ cidade contemporânea, os veículos automotores passaram a ser utilizados para todo tipo de deslocamento, até mesmo para percorrer curtas distâncias e realizar pequenas tarefas como ir a padaria ou a farmácia da esquina. Os automóveis, que se assemelham a pequenas bolhas artificiais, transmite aos usuários a falsa sensação de segurança. Dentro desta cápsula, num ambiente climatizado, os usuários sentem-se protegidos da violência urbana, da poluição, se isolam do espaço público e desfrutam de maior conforto e privacidade. Com todas estas vantagens, é claro, no final do mês verifica-se que usar o automóvel particular sai caro. Gasta-se com combustível, estacionamento, seguro, impostos e se o motorista não for prudente haverá de pagar as multas e despesas com mecânicos e funilaria. 


\section{Periódica Eletrânica

A pesquisa realizada na Avenida João Pessoa, embora represente uma pequena amostra da circulação urbana brasileira, comprovou que os problemas ambientais e urbanos de Guaratinguetá são semelhantes aos das metrópoles, ainda que em menor escala, apresentam tendência de se agravar.

$\mathrm{O}$ uso de carro de passeio para trabalhar deve ser evitado. Melhorar e incentivar o estacionamento de veículos na Avenida João Pessoa trará maior congestionamento. Deve-se concentrar esforços para diminuir a quantidade de carros que circulam pela Avenida.

O leito carroçável da Avenida João Pessoa encontra-se em bom estado de conservação, já as calçadas estão esburacadas, irregulares apresentando grande contraste se comparadas ao leito carroçável. Isto demonstra a prioridade dada ao transporte motorizado, certifica o incentivo a cultura do automóvel.

$\mathrm{Na}$ Avenida João Pessoa devido ao comércio e as moradias a prioridade é do pedestre. Portanto, deve-se implantar ciclovia, melhorar o transporte público e os pontos de ônibus.

Também é importante implantar a mão única para o tráfego dos veículos, cobrar pelo estacionamento, reformar e padronizar as calçadas a fim de aumentar a segurança do pedestre e melhorar o escoamento das águas pluviais.

Ao longo da Avenida João Pessoa deve-se permitir a construção de residências, bem como em seu entorno. Incentivar pedestres a utilizarem o transporte coletivo e a bicicleta, que são meios de transporte sustentáveis. Deve-se criar bicicletários e implantar radares para o controle da velocidade dos veículos e melhorar a fiscalização. Melhorar as calçadas e criar rampas de acesso para cadeirantes, instalar lixeiras para coleta seletiva, refazer o paisagismo da avenida.

O rio Paraíba do Sul confronta com a avenida em aproximadamente um quilômetro. As margens do rio encontram-se densamente arborizadas e embora o rio esteja poluído, muito contribui para tornar, neste trecho, a avenida mais agradável.

A construção de uma cidade sustentável exige a conscientização dos cidadãos sobre a importância de se construir e preservar o espaço público, de se melhorar e humanizar a circulação urbana, de maneira que todos: pedestres, ciclistas e motoristas possam conviver e circular pela cidade com mais respeito. As campanhas educativas são indispensáveis, principalmente para crianças que se encontram em fase de formação de sua cidadania. 


\section{Periódica Eletrânica

\section{BIBLIOGRAFIA}

BOARETO, Renato. A política de mobilidade urbana e a construção de cidades sustentáveis. Ciência \& Ambiente. Santa Maria: n.37, p. 73-92, jul./dez. 2008.

LAGONEGRO, Marco Aurélio. A ideologia rodoviarista no Brasil. Ciência \& Ambiente. Santa Maria: n.37, p. 39-50, jul./dez. 2008.

SCHOR, Tatiana. Da rabeta ao $4 \times 4$ : A expansão da modernidade (e de seu colapso) na fronteira norte do Brasil. Ciência \& Ambiente. Santa Maria: n.37, p. 61-72, jul./dez. 2008.

CARTA de Atenas. Congresso Internacional de Arquitetura Moderna, Nov. 1933.Disponível em: < http://portal.iphan.gov.br/portal/baixaFcdAnexo.do?id=233>. Acesso em: 10 novembro de 2014.

HERMANN, Lucila. Evolução da estrutura social de Guaratinguetá num período de $\mathbf{3 0 0}$ anos, 1945, São Paulo.

OLIVEIRA, Bruno Couto. Alternativas sustentáveis para a circulação urbana - estudo de caso: as cidades de Guaratinguetá e Lorena. 2011. 73 f. Trabalho de Graduação (Engenharia Civil) UNESP Guaratinguetá, 2011.

PIRES, Ailton Brasiliense; VASCONCELOS, Eduardo Alcântara; SILVA, Ayrton Camargo. Transporte Humano-cidades com qualidade de vida. São Paulo: Associação Nacional de Transportes Públicos, 1997. 312p.

BRASIL. Ministério do Meio Ambiente. Mobilidade Sustentável. Disponível em $<$ http://www.mma.gov.br/ cidades-sustentaveis/urbanismo-sustentavel/mobilidadesustent\%C3\%A1vel>. Acesso em 19/12/2014.

BURKE, Bill; KEELER, Marian. Fundamentos de projeto de edificações sustentáveis. 1a ed.: Bookman, 2010. 362 p.

CANEPA, Carla. Cidades sustentáveis: o município como locus da sustentabilidade. $1^{\text {a }}$ ed. São Paulo: RCS Editora, 2007. 293 p.

CARVALHO, Samantha Oliveira Dias de. Análise comparativa entre os bairros do Pedregulho e Santa Luzia, cidade de Guaratinguetá, e sugestões de alternativas sustentáveis. 2013. $73 \mathrm{f}$. Trabalho de Graduação (Engenharia Civil) - UNESP Guaratinguetá, 2013.

JACOBS, Jane. Morte e Vida de grandes cidades; - São Paulo: Martins Fontes, 2000.

MANUAL de procedimentos para o tratamento de polos geradores de tráfego. Departamento Nacional de Trânsito/Fundação Getúlio Vargas, Brasília, 2001. Disponível em: < http://www.denatran.gov.br/publicacoes/download/PolosGeradores.pdf >. Acesso em 10 jan. 2015. 